\title{
Quando o eleitor faz a propaganda política: 0 engajamento popular na campanha eleitoral de Jânio Quadros (1959-1960)*
}

Jefferson José Queler ${ }^{* *}$

Neste artigo, analiso aspectos da atuação de Jânio Quadros quando disputou as eleições presidenciais em 1960. Critico o sentido de sua imagem profundamente enraizada de líder populista, apontando como tal atributo lhe foi dado notadamente por seus inimigos. Após isso, também pretendo indicar como muitos de seus apoiadores não foram manipulados por ele nem por uma suposta máquina de propaganda. Por meio de cartas que lhe foram enviadas, é possível perceber como muitas pessoas produziram e distribuíram propaganda política por si próprias. Isso pode ser visto em vários poemas, canções, panfletos ou discursos ecoados publicamente, que defendiam Jânio da mesma forma que suas ações e projetos políticos.

Palavras-chave: Opinião Pública - Propaganda Política - Comunicação Oral

Political campaign made by voters: the popular engagement in the Janio Quadros voting campaign (1959-1960)

In this article I analyze some aspects of the political performance of Jânio Quadros when he ran for president in the 1960 elections. I criticize the meaning of his deeprooted image as a populist leader, by pointing out how such attribute was given to him mainly by his enemies. Furthermore, I also intend to indicate how many of his

\footnotetext{
* Artigo recebido e aprovado para publicação em julho de 2009.

** Doutor em História pela UNICAMP. E-mail: jeffqueler@hotmail.com.
} 
supporters were not manipulated by him, or by an alleged propaganda machine. Through letters sent to him, it is possible to see that many people produced and distributed political propaganda on their own account. This can be seen in publicly echoed poems, songs, pamphlets or speeches defending Jânio and his political actions and projects.

Keywords: Public Opinion - Political Propaganda - Oral Communication

Lorsque l'électeur fait la propagande politique : l'implication populaire dans la campagne électorale de Jânio Quadros (1959-1960)

Dans cet article j'analyse quelques aspects de l'action de Jânio Quadros à l'occasion des élections présidentielles en 1960. Je critique le sens de son image profondément enracinée de leader populiste, en signalant comment cet attribut lui a été donné, notamment par ses ennemis. Ensuite, je cherche à démontrer qu'une grande partie de ses sympathisants n'ont nullement été l'objet de manipulations, ni par le propre candidat, ni par une soi-disant machine de propagande. En consultant les lettres qui lui ont été envoyées, il est possible de constater qu'un grand nombre de personnes ont créé et distribué eux même de la propagande politique. Cette affirmation est évidente dans les divers poèmes, chansons, pamphlets ou discours dont ils se faisaient publiquement l'écho, défendant Jânio, ses actions e ses projets politiques.

Mots-clés: Opinion Publique - Propagande Politique - Communication Orale

A propaganda, quando não se entrega a um blefe mentiroso, quando é utilizada sadiamente, não é nada mais do que a explicação e a justificação de uma política. Em troca, ela obriga a política a se definir e a não se contradizer, o que é prestar-lhe um grande serviço. (Jean-Marie Domenach, La propagande politique, Paris, Presses Universitaires de France, 1950, p. 83.)

\section{Qual propaganda política?}

Quando surge nas páginas da imprensa ou na historiografia nos dias de hoje, muitas vezes a figura de Jânio Quadros é invocada com o intuito de rechear o anedotário da política nacional com os atos de um político tido como demagogo, prestidigitador e excêntrico. Alguém que, como presidente da República, proibiu o uso do biquíni nas praias brasileiras e as brigas de galo, para renunciar depois de oito meses de mandato, é tomado frequentemente como uma pessoa desequilibrada. No entanto, pouco ou quase nada se questiona o quanto tais assertivas podem ter sido construídas por seus adversários 
políticos durante aquele período. Ademais, seria possível vislumbrar alguma forma de participação política entre aqueles que contribuíram para a ascensão dessa liderança?

Neste artigo, pretendo analisar algumas das razões para a consolidação da força política de Jânio Quadros durante o período em que disputou as eleições presidenciais brasileiras entre os anos de 1959 e $1960 .{ }^{1}$ Através da correspondência por ele recebida, procuro investigar algumas formas pelas quais simpatizantes de sua candidatura manifestaram-lhe apoio, principalmente através da produção e distribuição de propaganda política de forma voluntária. Tentando evitar conclusões apressadas acerca desse controvertido personagem da história política brasileira, frequentemente tratado como paradigma de líder "populista", apontarei algumas razões pelas quais ele foi levado a sério, naquelas circunstâncias, por amplos setores da sociedade.

Jânio da Silva Quadros (JQ) nasceu em Campo Grande, no então estado de Mato Grosso, em 1917, filho de Leonor da Silva Quadros e do médico Gabriel Quadros. ${ }^{2}$ Após passagens e curtas permanências em Curitiba e em diversas cidades do interior paulista, a família Quadros estabeleceu-se em São Paulo, onde, em 1933, JQ ingressou no Colégio Arquidiocesano, ali permanecendo até o término de seus estudos secundários. Em seguida, passou a frequentar o curso da Faculdade de Direito, bem como a lecionar português e geografia em algumas escolas.

Nesse momento, conheceu Eloá do Vale - filha de um farmacêutico amigo de seu pai -, com quem se casaria após conseguir seu diploma. Suas atividades profissionais se concentraram então em torno de um pequeno escritório de advocacia e em aulas ministradas nos tradicionais colégios Vera Cruz e Dante Alighieri; as tarefas de docente contribuíram para granjear-lhe apoio de pais e alunos para o primeiro cargo público por ele disputado, pela legenda do Partido Democrata Cristão (PDC), em 1947: a vereança de São Paulo. Saindo do pleito com 1.704 votos, ficou apenas com uma vaga de suplente. A posterior cassação do mandato de deputados ligados ao Partido Comunista do Brasil (PCB), por fim, deu-lhe a chance de atuar como vereador.

\footnotetext{
${ }^{1}$ A análise e as hipóteses que se seguem foram por mim desenvolvidas em minha tese de doutorado, orientada pela Prof ${ }^{\mathrm{a}}$. Dr ${ }^{\mathrm{a}}$. Vavy Pacheco Borges e financiada pela FAPESP. Cf. Jefferson José Queler, Entre o mito e a propaganda política: Jânio Quadros e sua imagem pública (1959-1961), Campinas, IFCH/ Unicamp, 2008.

${ }^{2} \mathrm{O}$ verbete sobre JQ no Dicionário Histórico-Biográfico Brasileiro, organizado e publicado por equipe ligada ao Centro de Pesquisa e Documentação de História do Brasil (CPDOC), oferece uma série de informações sobre os primeiros anos de sua vida.
} 
Nos anos seguintes, é notável como ele galgou posições mais elevadas num período relativamente curto de tempo; nos próximos treze anos, para ser mais preciso: deputado estadual, prefeito de São Paulo, governador de São Paulo, deputado federal e presidente da República. Depois de tomar posse deste último cargo no início de 1961, governou o país durante oito meses e, em circunstâncias ainda em grande parte nebulosas, renunciou a seu mandato. É provável que este ato tenha contribuído para erodir grande parte da credibilidade outrora conquistada por ele na sociedade brasileira, conferindo-lhe o estatuto de piada nacional, conforme sugere relatório oficial da embaixada britânica enviado a Londres, datado de 19 de abril de 1962:

A estrela política de Jânio Quadros parece estar afundando numa poça de uísque. (...) Uma piada que se conta aqui - e não é exatamente uma piada - é que 'forças ocultas', que Jânio culpou pela renúncia, saíram de uma garrafa. Frequentadores de bar agora pedem ao barman que lhes sirvam 'forças ocultas' com soda. (...) Como quase tudo é possível na política brasileira, pode ser que ele recupere terreno tão rapidamente quanto perdeu. ${ }^{3}$

Este tom de zombaria em relação tanto a JQ quanto ao eleitorado brasileiro delineia uma análise que não nos permite entrever possíveis atrativos da imagem pública daquele político perante setores da sociedade nos anos anteriores. Mais do que isso, tais afirmações estão afinadas com uma posição muito comum entre adversários de JQ, explicitada em contextos e situações diversos ao longo de sua carreira pública: a de que ele seria uma farsa política. Cabelos despenteados, barba crescida, roupas amarrotadas, gravatas desalinhadas, sotaque peculiar, gesticulação intensa e sanduíches de mortadela levados nos bolsos e comidos em momentos oportunos são alguns dos recursos que teriam levado esse "demagogo" ao topo da política nacional; manipulando as "massas" supostamente despreparadas para o exercício da cidadania.

Essa problemática surgiu durante pesquisa anterior, na qual estudei a atuação política do jornal Última Hora-RJ (UH) nos últimos anos do governo Kubitschek. ${ }^{4}$ Ao abordar o período, pude acompanhar opiniões veiculadas

${ }^{3}$ Documento FO 371/162.132 do Public Record Office. Apud: Geneton Moraes Neto, Dossiê Brasil. As histórias por trás da história recente do país, Rio de Janeiro, Ed. Objetiva, 1997, p. 79.

${ }^{4}$ Jefferson José Queler, Democracia e Desenvolvimento: os posicionamentos politicos do jornal Última Hora no governo Kubitschek (1957-1960), Campinas, IFCH/ Unicamp, 2004. Este estudo foi orientado pela Prof ${ }^{a}$. Dr ${ }^{a}$. Vavy Pacheco Borges e contou com o financiamento do CNPq. 
naquele periódico sobre a campanha eleitoral então corrente para a Presidência da República. Desenrolando-se na prática desde o início de 1959 e prolongando-se até outubro de 1960, a disputa centrou-se nos candidatos Adhemar de Barros, JQ e o Marechal Henrique Teixeira Lott. Sendo o candidato defendido pelo jornal este último, pouco a pouco fui tomando contato com um ferrenho opositor da candidatura janista. De forma geral, a projeção de JQ na política nacional era considerada como provindo do êxito de uma propaganda meticulosamente organizada e planejada; e o sentido atribuído a esta última recaía sobre o que seria seu potencial para mistificar o eleitorado e a população em geral.

Um exemplo disso pode ser notado em comentários da colunista Adalgisa Nery sobre greves ocorridas no estado de São Paulo e o suposto paradoxo da grande popularidade de JQ ali:

São Paulo com a pletora de greves que assoberbam o atual governador esclarece a todos os brasileiros de que não há absolutamente o equilíbrio econômico e financeiro propalado com tanta ousadia e irresponsabilidade pelos fascinados janistas. (...). O fenômeno não é o gari mato-grossense e sim a obliteração sensorial do povo paulista, que sendo considerado no país como o mais avançado industrialmente é, por incrível que pareça, o mais retardado em politização. Só há uma explicação para esse fenômeno: a desidratação da sua mentalidade, consumada pela propaganda dos grupos econômicos estrangeiros. ${ }^{5}$

Desse modo, apoiando-se em tal artifício e servindo-se de recursos como demagogia e prestidigitação, ele conseguiria fortalecer e consolidar sua presença no cenário político do país. Ora, tanto no discurso da UH quanto na historiografia permanece a ideia de que JQ tenha se promovido no âmbito da política brasileira através da mistificação de sua imagem junto à população; prevalece ainda a interpretação de que isso teria acontecido apenas graças a seu personalismo e a sua capacidade de representar papéis em público. Trata-se de um caso, portanto, em que a mitologia veiculada por seus opositores parece ter sido bem-sucedida em incorporar-se nas ciências sociais e na historiografia. ${ }^{6}$

\footnotetext{
${ }^{5}$ Adalgisa Nery, "Equilíbrio mentiroso", Última Hora, Rio de Janeiro, 21/04/59, p. 02 (tablóide).

"JQ é tratado como uma manifestação do "populismo" na política brasileira, de forma matizada, nas seguintes obras: Francisco Weffort, O Populismo na Política Brasileira, Rio de Janeiro, Paz e Terra, 1978; Thomas Skidmore, Brasil: de Getulio a Castelo (1930-1964), Rio de Janeiro, Paz e Terra, 1988; Maria Victoria de M. Benevides, O PTB e o trabalhismo: partido e sindicato em São Paulo (1945-1964), São Paulo, Ed. Brasiliense, 1992; Vera Chaia, A liderança política de Jânio Quadros (1947-1990), Ibitinga, Humanidades, 1991.
} 
Em tais perspectivas, os autores utilizam quase sempre o termo "populismo" na condição de conceito explicativo para o que seria a manipulação das "massas" por lideranças demagógicas. Nesse sentido, o balanço e as reflexões de Jorge Ferreira, no que diz respeito ao tratamento crítico do populismo enquanto conceito ou fenômeno, oferecem um encaminhamento importante para este estudo. ${ }^{7}$ Tratada sob um viés histórico, essa noção está associada à migração de trabalhadores rurais para os centros urbanos, bem como ao modo como os mais diversos analistas os concebiam como despreparados para realizar ações coletivas ou comportar-se politicamente; o autor indica então como, sob as mais diversas perspectivas teórico-metodológicas, ao longo dos últimos anos, o "populismo" vem sendo problematizado como fenômeno, passando a figurar, antes, na condição de categoria imaginada para explicar a política do país.

Estou de acordo com o autor e esta tendência de pensamento, e também procurarei sugerir como a noção de populismo não dá conta de explicar a ascensão de JQ na política brasileira. Procurando abandoná-la, trabalharei com a hipótese de que sujeitos políticos tomaram parte na conformação da força política do personagem. Ao deparar com discursos que fundamentam o poder pela técnica e pela racionalidade - justamente no que concerne a uma suposta máquina de propaganda janista onipresente e onipotente -, bem como com os diversos usos feitos da propaganda política pelos consumidores, optei por tratar dessas questões com o auxílio das reflexões de Michel de Certeau sobre os pequenos desvios de pessoas comuns diante do poder e da disciplina. ${ }^{8}$

Em outras palavras, se a rede de "vigilância" se espraia e atua sobre uma formação social, tanto mais necessário se torna descobrir como uma sociedade inteira não se reduz a isso; é preciso investigar como possíveis procedimentos populares, em “operações quase microbianas”, desviam-se dos mecanismos da disciplina ou jogam com eles para alterá-los. Desse modo, avaliarei a hipótese de que a propaganda em torno da figura de JQ não foi obra exclusiva de uma estrutura tecnocrática, mas foi também obra coletiva de diversos grupos sociais; pessoas que empregaram táticas como produzir e divulgar material publicitário ou distribuir material propagandístico oficial em nome do candidato, com o intuito de realizar futuramente seus interesses materiais e simbólicos no âmbito da arena política.

${ }^{7}$ Jorge Ferreira, "O nome e a coisa: o populismo na política brasileira", in: Jorge Ferreira (org.). O populismo e sua história, Rio de Janeiro, Civilização Brasileira, 2001, p. 59-125.

${ }^{8}$ Michel de Certeau, A invenção do cotidiano. 1. Artes de fazer, Petrópolis, Vozes, 2004, p. 41. 
Essas questões surgiram a partir da leitura de cartas populares enviadas a JQ durante o período em que disputou as eleições presidenciais. Esse material foi consultado no arquivo pessoal de José Aparecido de Oliveira, então secretário particular do candidato, em Conceição do Mato Dentro-MG. São 5.345 cartas organizadas de acordo com as datas nelas expostas..$^{9}$ Além de pedidos, tais missivas veiculam conselhos e manifestações de apoio ao candidato, os quais serão particularmente enfatizados nas páginas seguintes. Com isso, penso ser possível apontar não apenas a ação dos missivistas em tentar manipular as ideias presentes no discurso oficial para a realização de seus interesses, como empregos e outros benefícios, mas também representações socialmente aceitas de JQ e práticas políticas como aquelas indicadas anteriormente. ${ }^{10}$

Ainda que o personalismo de JQ possa ter sido um importante instrumento para a mobilização do eleitorado, é preciso destacar que ele serviu-se de projetos políticos e instituições partidárias para consolidar sua força política. A atuação de partidos em sua candidatura contou com a participação de membros de grande parte das agremiações existentes, destacando-se o papel de integrantes da União Democrática Nacional (UDN), que aderiu à coligação janista notadamente sob o entusiasmo do grupo vinculado a Carlos Lacerda.

As atividades da campanha janista também receberam apoio e recursos de muitos empresários, muitos deles ligados ao capital estrangeiro, com especial destaque para o Conselho Nacional das Classes Produtoras (CONCLAP) e os grupos Votorantin, Matarazzo, Associação Comercial, Federação das Indústrias, Indústria Automobilística de São Paulo, Federação das Associações Rurais e Moinho Santista. ${ }^{11}$

No entanto, tais vínculos foram constantemente negados ou minimizados tanto por JQ quanto por sua equipe em público. Tendo como um de seus propósitos o de apresentar a candidatura janista como dissociada de partidos e políticos profissionais, simpatizantes de JQ criaram o Movimento Popular Jânio Quadros (MPJQ). A imagem pública dessa instituição foi apresentada do seguinte modo pelo seu então presidente, Castilho Cabral, em panfleto

\footnotetext{
${ }^{9}$ Tal arquivo foi organizado pela então Superintendente do Arquivo Público Mineiro, Edilane Carneiro, a quem devo muito por ter me orientado entre a documentação. É importante lembrar também que, na análise das cartas, manterei a grafia original dos remetentes, de modo a evitar a tentação de "corrigir" as fontes. Como as missivas estão ordenadas pelas suas datas, as referências serão dadas no corpo do texto.

${ }^{10}$ Sobre a análise de correspondência, ver: Roger Chartier, La correspondance: les usages de la lettre au XIXe siècle, Fayard, 1991.

${ }^{11}$ René Armand Dreifuss, 1964: a conquista do Estado, Petrópolis, Vozes, 1981, p. 71-82.
} 
intitulado "Não é instrumento de nenhum partido o MPJQ": “o M. P. J. Q. nasceu do idealismo de modestos funcionários, cresceu com a adesão de estudantes, de trabalhadores, velhos combatentes de alguns partidos, gente inconformada de tôdas as procedências (...)". ${ }^{12}$

Suas características e funções seriam a de "organização apartidária", atuando no "agrupamento do eleitorado independente, na multiplicação de comitês, contínua propaganda através de todos os meios de divulgação, organização de comícios, contribuição aos planos de campanha (...)". ${ }^{13}$ Por mais que tal movimento pudesse estar associado a determinadas formas de expressão política da população, dissociá-lo completamente de legendas partidárias era uma evidente tática eleitoral da equipe janista, baseando-se no pressuposto de que a rotulação da candidatura de JQ por esta ou aquela legenda lhe seria danosa.

Já no que diz respeito à apresentação de projetos políticos, JQ explicitou diversas propostas de governo em programas de rádio e televisão, em comícios e em jornais e revistas durante a campanha. ${ }^{14} \mathrm{Um}$ ponto muito enfatizado em seus discursos tratava do que seriam os efeitos perversos do desenvolvimentismo: este, apesar de ter acelerado a industrialização e o crescimento econômico do país, relegou-lhe uma inflação que de 19,2\%, em 1956, saltara para 30,9\%, em 1960, aumentando consideravelmente o custo de vida entre a população.

Segundo JQ, não caberia a discussão do desenvolvimento enquanto objetivo, tratado como aspiração do brasileiro em geral, mas do apontamento do crescimento econômico como sendo parcial. Por exemplo, no dia 8 de fevereiro de 1960, ele fez o seguinte comentário num programa televisivo no Rio de Janeiro, ao responder se iria cumprir cinquenta anos em cinco (um dos lemas do governo Kubitschek): "Não vejo metas que cuidem do homem, seja no ventre materno, seja na infância, na adolescência ou na maturidade. Observe-se a previdência social, os mocambos e as favelas. Não vejo metas que cuidem do homem do campo". ${ }^{15}$

Analisando outros aspectos do discurso janista, Miriam Limoeiro Cardoso identificou que, em meio a assertivas como a anterior acerca da valorização

${ }^{12}$ Arquivo pessoal Castilho Cabral, CPDOC-FGV, CCc 59. 04. 13, I-72.

${ }^{13}$ Ibidem.

${ }^{14}$ Uma análise dos discursos de JQ naquelas circunstâncias pode ser encontrada no seguinte livro: Miriam Limoeiro Cardoso, Ideologia do Desenvolvimento. Brasil: JK e JQ, Rio de Janeiro, Paz e Terra, 1978.

15 Vidal dos Santos \& Luiz Monteiro, Diário de uma campanha, São Paulo, Livraria Exposição do Livro, s/d., p. 149. 
do homem, o candidato declarava preocupações com a formação do "povo". ${ }^{16}$ Através desse expediente, JQ apresentava como tarefa sua contribuir para a politização e a elevação de consciências, com o propósito de transformar indivíduos em cidadãos de uma nação. Segundo a autora, seu trabalho político se apresentava em termos muito mais pedagógicos do que eleitorais: "ele busca o voto, sim, mas como consequência da adesão à causa que defende. Neste sentido a sua atitude é política na acepção precisa do termo". ${ }^{17}$

Da mesma forma que penso serem acertadas tais observações, sugeriria ainda que tais proposições do candidato guardam relações próximas com o ideário da democracia cristã, inspiração primeira do PDC, legenda pela qual JQ iniciou sua carreira política. Afinal, não se trata justamente de se propor a promoção de reformas no sentido de ampliar a participação política e defender melhores condições de vida entre as camadas mais pobres da população, com o propósito de impedir a luta de classes? Não se trata justamente de se propor uma experiência semelhante à do Partido Popular Italiano, partido laico mas inspirado na doutrina cristã, uma das instituições que contribuíram para o alargamento da base da classe dirigente na Itália, inserindo a massa popular católica no quadro institucional do Estado liberal? ${ }^{18}$

Em torno de tais princípios, JQ concentrou suas críticas à administração então vigente, atacando a corrupção, o desperdício de recursos com as obras de Brasília, a inflação, o aumento do custo de vida e o que seriam as futilidades do "presidente voador"; quadro este que o candidato prometia "limpar" com sua vassoura, símbolo máximo de sua campanha. É preciso salientar ainda que, além dessas denúncias, o candidato também apresentou outras propostas para viabilizar as transformações prometidas no interior do país, especialmente através de suas proposições para a chamada Política Externa Independente (PEI). ${ }^{19}$

Entre os princípios desta última, destacava-se a indicação de que não havia razões para o governo brasileiro deixar de promover trocas comerciais com países de regiões periféricas do mundo ou com regimes de orientação comunista. Outros aspectos marcantes da política externa proposta por JQ referiam-se à defesa do direito de autodeterminação dos povos e ao não alinha-

\footnotetext{
${ }^{16}$ Miriam Limoeiro Cardoso, op. cit. p. 306.

${ }^{17}$ Ibid.

${ }^{18}$ Mario Rossi, Da Sturzo a de Gasperi: profilo storico del cattolicesimo politico nel novecento, Roma, Editori Riuniti, 1985, p. 113.

${ }^{19}$ Miriam Limoeiro Cardoso, op. cit. p. 294-304.
} 
mento do Brasil a nenhum dos dois pólos da Guerra Fria, representados pela União Soviética e pelos Estados Unidos. Dessa forma, servindo-se de propostas e projetos políticos, JQ procurou diferenciar sua candidatura da administração Kubitschek e das demais candidaturas; o que fornece os primeiros indícios para a problematização da ideia de que seu personalismo e a propaganda política em torno de sua figura foram capazes de manipular o eleitorado.

\section{2 - Ritmos e sons na construção da imagem do líder}

O termo propaganda é associado frequentemente à promoção de mercadorias ou lideranças políticas através de meios de comunicação de massa, como o rádio, a televisão, os jornais e as revistas. Tal sentido acaba por deixar de lado um dos significados elementares do termo: o de difusão ou propagação; ou seja, desconsidera-se a existência de relações sociais face a face, traduzidas em ações de pessoas tentando convencer ou persuadir seus respectivos interlocutores acerca das vantagens de seus pontos de vista.

Antes de mais nada, é preciso lembrar que a grande maioria da população brasileira era então analfabeta, o que pressupõe uma discussão pública de ideias afinada com tal situação, caso admitamos a existência de participação política nessas circunstâncias. Como a alfabetização era um requisito para o exercício do voto, segundo a Constituição de 1946, $16 \%$ dos brasileiros puderam votar nas eleições presidenciais de 1945; essa porcentagem subiu para $24 \%$ em 1962..20 Em outras palavras, é possível imaginarmos a partir disso a importância de formas orais de comunicação entre a população, desde as relações face a face até a interação com tecnologias como o rádio e a televisão (esta ainda em seus primórdios no país) para a obtenção e a reelaboração de informações.

As características e os efeitos da comunicação oral na mente humana foram objeto de extensa análise entre autores como Eric A. Havelock e Walter Ong. ${ }^{21}$ Ambos sustentam que a consciência humana tem sido alterada ao longo do tempo, por intermédio notadamente de tecnologias como a escrita e a imprensa. Estas são apontadas como importantes instrumentos para a

${ }^{20}$ Dulce Chaves Pandolfi, "Voto e participação política nas diversas repúblicas do Brasil”, in: D. C. Pandolfi; A. C. Gomes, \& Verena Alberti (orgs.), A República no Brasil, Rio de Janeiro, Nova Fronteira/CPDOC, 2002, p. 97.

${ }^{21}$ Sobre esse assunto, destaco os três livros adiante: Eric A. Havelock, A revolução da escrita na Grécia e suas consequências culturais, Rio de Janeiro/São Paulo, Paz e Terra/Ed. UNESP, 1996; Eric A. Havelock, The muse learns to write: reflections on orality and literacy from antiquity to the present, London, Yale University Press, 1986; Walter Ong, Orality \&o Literacy: the technologizing of the word, London, Routledge, 2000. 
elaboração de um pensamento mais linear e conceitual; em contrapartida, preocupam-se também em identificar características ou manifestações de formas de comunicação oral. Segundo eles, existem muitas dificuldades para o pesquisador apontar traços de oralidade no passado, dado que sua principal fonte de investigação é textual. Mesmo assim, sustentam ser possível fazê-lo através da sintaxe e do modo como certos textos são construídos. Trata-se, antes, de sugerir a presença da oralidade na documentação escrita do que demonstrá-la, cabalmente, através de "fatos" ao modo de narrativas históricas

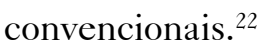

É claro que a oralidade abordada neste estudo não se refere ao que Walter Ong classifica como "oralidade primária”, a qual se refere a uma cultura totalmente intocada pela escrita ou pela imprensa. ${ }^{23} \mathrm{Na}$ verdade, trata-se da "oralidade secundária" - termo que admite o contato de uma cultura com tais tecnologias -, ou seja, de uma oralidade sustentada também por tecnologias como o rádio, a televisão, o telefone e outros dispositivos eletrônicos. Apesar dessas diferenças, o autor indica como as formas de consciência em ambas as situações apresentam muitas semelhanças, de modo que o estudo de uma pode iluminar a compreensão da outra.

De modo geral, W. Ong chama a atenção para a questão da memorização de informações num ambiente social em que as pessoas não registram seus pensamentos por meio da escrita. Em tais circunstâncias, lembrar e reter formulações laboriosamente construídas exigem a recorrência a padrões mnemônicos marcados profundamente pelo ritmo, notado sob a forma de repetições, antíteses, aliterações e assonâncias, epítetos, provérbios, fórmulas e padrões temáticos e linguagem versificada. ${ }^{24}$

É importante ressaltar que traços de oralidade podem ser facilmente encontrados em falas do próprio JQ. Por exemplo, um de seus mais célebres discursos, proferido por ocasião da aceitação de seu nome como candidato presidencial a ser apoiado pela UDN, é tecido do seguinte modo:

Não creio nas concessões demagógicas. Não creio na mentira das promessas. Não creio nos sufrágios da fraude. Não creio nos desmaios da autoridade. Não creio na desordem administrativa. (...) Creio, sim, no império da Constituição.

${ }^{22}$ Sobre o estatuto epistemológico deste tipo de investigação, E. Havelock adverte o seguinte: "É óbvio que é impossível provar esta tese por métodos positivistas: a linguagem oral não produz fósseis". Cf. Eric A. Havelock, A revolução....., p. 14.

${ }^{23}$ Walter Ong, op. cit. p. 11.

${ }^{24}$ Ibid., p. 34. 
Creio na nobreza da Magistratura Suprema. Creio na autenticidade das Casas Legislativas. Creio na moeda sadia, com a qual se pague a despesa corrente e se amealhe o pecúlio de amanhã. Creio no proletariado consciente. Creio na opinião garantida pelas franquias (..... ${ }^{25}$

O discurso é construído com o recurso de antíteses e justaposições de frases iniciadas pelas formas expressivas "Creio" e "Não creio", marcantes indícios de que o público por ele visado transcendia as fileiras udenistas, sendo também buscado entre os setores da população pautados, em grande medida, pela oralidade.

De certo modo, é possível que esse discurso e outros do gênero tenham sido bem-sucedidos em atingir tais pessoas, conforme sugerem algumas considerações presentes na carta de Luiz Góes, enviada da cidade do Rio de Janeiro em 9 de novembro de 1959:

Permita-me V. Excia. dizer que o estilo do vosso discurso 'Não Acredito' e 'Eu acredito...' formou duas chaves bem distintas, facilitando assim, ao povo sua compreensão.(...) no proximo discurso V. Excia, deverá uzar uma nova chave: 'O Brasil para encontrar a sua redenção não precisa dos descrentes (...) não precisa de lamber as mãos dos politicos que representam as grandes Nações do Mundo, não precisa, muito menos, de tolerar, nem perdoar, os ladrões internos e externos da Nação Brasileira, etc...etc... Agora contrapondo-se dirá: o Brasil conduzido pelos homens patriotas da UDN precisa de:.... precisa de:....' (...).

E ele segue trazendo outras informações curiosas:

A descrença do homem da rua é tão grande que, ouve-se constantemente da boca do povo a seguinte sentença: 'De 1930 para cá, a cueca suja de político é a toalha de rôsto do outro'. (...).

Em meio a sugestões sobre a formulação dos discursos de JQ e críticas ao governo e aos políticos de forma geral, o missivista fornece indícios sobre o modo pelo qual se processava parte do debate público. Tanto seu elogio ao discurso, baseado em antíteses e fórmulas expressivas, quanto a alusão de que a população servia-se de slogans para criticar os políticos e os partidos são, conforme visto anteriormente, sinais de composição comuns em textos que indiciam a presença de formas orais de comunicação. Em outras palavras, num momento em que a alfabetização era uma das condições para o exercício

${ }_{25}$ Íntegra do discurso em: Castilho Cabral, Tempos de Jânio e outros tempos, Rio de Janeiro, Ed. Civilização Brasileira, 1962, p. 168. 
formal da cidadania, tal fonte fornece pistas de como pessoas pouco ou quase nada familiarizadas com a escrita estavam discutindo e fazendo política.

Ademais, não parece ser casual que, em meio à mencionada correspondência, abundam exemplos de textos com linguagem versificada dirigidos a $\mathrm{JQ}$, recursos para se reter informações com maior facilidade na memória num ambiente em que não se armazena, pelo menos com frequência, conhecimento por meio da escrita. De início, vejamos o exemplo da carta de Christina Brasilia Pagani, enviada de São Paulo-SP em 13 de outubro de 1960, na qual ela afirma:

agora que a V. Excia. atingiu o ponto mais elevado na politica, não pude resistir ao desejo de mandar uns versos que compus sobre a V. Excia desde a referida data até agora (...). Eu, 'pequenina e humilde' industriaria, espero que agora mais do que nunca V. Excia seja o homem que Diogenes procurava. (...)

Após esta demonstração de apreço por JQ, a missivista expõe os seguintes versos:

Sobre a S Excia Dr Janio Quadros (...)

Chamam-no de cabeludo

De magro, de feio, de tudo

Até de debil mental

Porem com toda sua 'feiúra'

É o maioral na prefeitura, (...)

Ainda mais, conforme fôr,

Do Estado será governador! (...)

Mais uma vez vencedor,

Do Estado tornou-se governador! (1955)

E na opinião de muita gente

Da Nação será Presidente! (...)

Estes são versos enviados diretamente a JQ como forma de homenageálo, o que de modo algum quer dizer que composições do gênero não circulassem também entre a população: ações em que autores pouco conhecidos ou anônimos distribuíam alguns de seus versos para discutir questões de caráter político ou promover o candidato de sua preferência.

É o que se pode sugerir a partir de trecho da missiva de Domingos Alves do Campo, identificada como sendo de Fortaleza-CE e datada de 11 de 
outubro de 1960; um caso que, a meu ver, corrobora a relação entre linguagem metrificada e memorização de informações:

Quase disiludido 'das coisas e dos homens', compreendi que só Jânio Quadros, poderia dar um jeitinho neste Brasil desgraçado! E por isso, fiz aqueles versos que mandei para V. Excia., e de que muito gostou o povo. (...) Destribuí todos até mesmo o que eu tinha como memoria, tal foi a procura. A minha situação financeira não permitiu que os imprimisse em milheiros, o que era o meu desejo. Para tê-los de memoria, vou pedir cópia a um funcionário do D. C. T., e assim poderei revê-los, para retoca-los (...) lembro-me ainda dos dois primeiros e ultimo, os quais quero reproduzir (...).

De fato, o remetente enviou os poemas anexados à carta, os quais veiculam críticas ao governo notadamente pelo que seria a sua condescendência com a corrupção, e apontam JQ como a solução para tais problemas. Isso é um significativo indício de atividade política, envolvendo a identificação de um candidato tido como apto a alterar os rumos da administração pública e a propagação desse ponto de vista junto a outras pessoas. $\mathrm{E}$ a grande quantidade de casos como esse, em que pessoas se anunciam como propagandistas voluntários da candidatura janista, ainda que nos alertem sobre a possibilidade de muitas delas estarem blefando com o intuito de obter favores em troca, lembra-nos que dificilmente alguém tentaria convencer JQ com isso se tal prática não fosse amplamente comum e disseminada.

Ainda que tais práticas tragam consigo evidências de atividades políticas, é preciso lembrar que alguns versos traziam consigo representações autoritárias do governante. Composições deste tipo, inclusive, circularam na imprensa, conforme aponta a missiva enviada de Porto Alegre-RS por Maria Alzira Rodrigues, em 3 de dezembro de 1960. Ela envia uma poesia a JQ afirmando que a mesma "brotou de meu coração, que não sendo de poetisa, é de boa brasileira"; afirma ainda que os versos foram publicados no vespertino "Fôlha da Tarde". Com efeito, junto da carta vem um recorte de jornal com os seguintes versos:
JANIO QUADROS
Problemas cruciantes, dominando a época!
Ébria de sangue a Rússia comunista;
Fome, miséria, guerra, tudo à vista,
E o riso alucinante dum cruel déspota. 
Moderno líder, de moderna raça, Luz de sapiência às turbas ignotas; (...)

É belo, é grande, e colossal, é novo, Jânio Quadros transformado em astro, Uma vassoura libertando um povo!

Nestes versos, JQ é tomado como um líder capaz de se contrapor à suposta ameaça da Rússia comunista. Ademais, por meio da metáfora da luz, ele é tratado como um líder dotado de grande sabedoria para conduzir uma multidão desorganizada de pessoas, as quais seriam desprovidas de conhecimento suficiente para reger seus destinos com autonomia. Ora, ao mesmo tempo em que esse exemplo sugere que concepções autoritárias sobre o governo encontravam respaldo entre determinados setores da população, ele também não seria significativo por indicar que havia uma pluralidade de significados atribuídos a JQ, e assim debates sobre o significado da figura deste último?

Um exemplo de debate de ideias através de linguagem metrificada, desta vez sobre a melhor forma de se conduzir a administração pública, pode ser vislumbrado em folheto do "sertanejo" Cunha Neto, enviado de Betim-MG em 19 de outubro de 1960, que parece ser um impresso de literatura de cordel. Iniciando os versos pedindo a Deus que o inspire com rimas suficientes para tratar do presidente eleito, o remetente traça uma pequena biografia de JQ em versos. Após tratar das experiências deste último como vereador e deputado, ele prossegue do seguinte modo:

Assim sendo, Janio tornou-se

Um politico de valor

Da classe operariado

Sempre foi o protetor (...)

Janio, provou que era

Governador monumental,

Movimentou o comércio

Do interior a capital

Melhorou a agricultura

E o parque industrial. (...)

Há anos vivemos sofrendo 
Com a infeliz inflação

Muita gente passa fome

Pois não pode comprar pão (...)

Que vossa excelência ampleie

Com urgência, a produção

Empréstimo ao agricultor

P'ra melhorar seu padrão (...)

Nestes versos, há a veiculação de críticas ao governo e a identificação de JQ como alguém capaz de solucionar determinados problemas à frente do governo, especialmente aqueles das camadas mais baixas da população, seja por suas atuações passadas como político, seja por suas características pessoais.

Entre as diferentes formas de linguagem versificada e rítmica que marcaram a campanha janista, também merece destaque a presença de diversas músicas e marchinhas carnavalescas entre a população. A música oficial composta para promover a figura de JQ, a célebre "Varre, varre, vassourinha", já enfatizava o tema da moralização administrativa a partir do símbolo máximo do candidato. Além da larga utilização desta composição pelos partidários da candidatura de JQ, outras canções surgiram e parecem ter circulado para promover a imagem dele. Isso aparece numa passagem da carta de Paulo Anselmo ao então presidente eleito, identificada como sendo de Goiânia-GO e datada de 10 de dezembro de 1960:

Fervoroso admirador de V. Excia., tendo colaborado com todas as minhas forças na campanha que o elegeu Presidente da República, inclusive compondo duas marchinhas, que, gravadas na Rádio Brasil Central, foram utilizadas em seus comícios posteriores ao de Goiânia, e desejando ter a honra de falar-lhe pessoalmente, venho solicitar-lhe a concessão de uma audiência (...).

O autor enviou as letras das duas marchinhas, das quais cito a que associa JQ explicitamente a uma proposta de governo:

Sou candidato, tira o nome da jogada,

Desista dessa e não pense no Alvorada,

Este conselho eu vou lhe dar, já sei porquê,

Para o lugar de JK vem JQ!

Nossa caçula é o orgulho da Nação,

Todo eleitor tem que saber em quem votar, 
A 3 de Outubro, na próxima eleição,

Com JQ, Brasília vai continuar (mas devagar!)

Curiosamente, JQ é tomado como o continuador da administração Kubitschek nessa canção. Isso pode ser explicado, em parte, devido aos declarados interesses do remetente em que o primeiro dê continuidade às obras de Brasília, as quais de algum modo parecem lhe ter beneficiado.

Já na letra da marchinha enviada de Glória-BA por José da Silva para comemorar a vitória de JQ nas urnas, em 11 de outubro de 1960, é a imagem do candidato de oposição que salta aos olhos:

A nossa oposição está contente

Com o pleito que terminou

Vamos minha gente cantar de alegria ô ô ...

Quando Jânio resolve

Varrer sujeira, não há quem dê jeito

Varre o comunismo, varre o P.S.D.

E no fim ei! tá tudo OQ (...)

Nesta canção, que também retoma o tema da moralização pública, JQ é tratado como o opositor tanto de uma doutrina, o comunismo, quanto de um partido, o PSD. Esses são, pois, alguns exemplos entre as diversas letras de músicas enviadas a JQ, algumas das quais vinham até mesmo acompanhadas de partitura. O que é particularmente importante frisar a partir dos exemplos anteriores é que propagar a imagem do candidato de sua preferência de forma voluntária, naquelas circunstâncias, era prática corrente entre muitas pessoas e localidades do país; e tais ações eram, por sua vez, acompanhadas de debates públicos sobre os rumos do governo.

\section{Usos e apropriações da propaganda política}

A participação de setores da população na elaboração da propaganda em torno da figura de JQ pode ser mais bem esclarecida. Em muitos casos, pessoas se apresentaram como propagandistas voluntários do mesmo sem aparentes vínculos com partidos ou com o MPJQ. Há indícios, pois, de que 
tais ações podem ter sido conduzidas de acordo com os interesses pessoais e políticos das pessoas nelas envolvidas.

O próprio JQ conclamava a população a atuar dessa maneira. É o que se pode notar no discurso proferido por ele no bairro do Tatuapé, na cidade de São Paulo, em 22 de julho de 1960:

Trabalhadores! As reformas de que a Nação carece eu não poderei promovê-las se não contar (...) com a assistência de cada um. (...) que cada um saia daqui convertido em um marechal de nossa luta, em um marechal da nossa cruzada, em um marechal dos nossos desejos, que cada um saia convertido em um chefe político. (...) Se cada um contribuir com alguns pobres cartazes que mandar fazer, nas pobres faixas que mandar pintar, se cada um contribuir na catequese das esquinas, das fabricas, na catequese das feiras, se cada um fôr um aposto, se cada um fôr um evangelizador, se cada um procurar trazer para nós cada irmão nosso (...) nós poderemos (...) conceder aos brasileiros os dias melhores a que eles têm direito (..... ${ }^{26}$

Assim como os versos e músicas anteriormente analisados indicam a existência e a circulação de um tipo de propaganda política extraoficial em nome de JQ, é possível identificar também a presença de panfletos e discursos a favor dele produzidos voluntariamente em diversas localidades do país. É o que indica o trecho de um panfleto enviado em anexo à carta de Orlando Kempi, de Cruzeiro do Sul-PR, em 4 de julho de 1960:

PRESIDENTE NOSSO, que estaes no ar, voador seja o vosso nome, seja feita a vossa viagem, assim de Avião, como de Elicóptero o feijão nosso de cada dia, e um pedacinho de carne, de vez em quando nos dae hoje....perdoai a nossa revolta, assim como nós perdoamos aos vossos eleitores......não nos deixeis morrer de fome, e livrae-nos do Lott, AMEM (...).

Após fazer essas críticas ao governo, o autor associa a figura de JQ aos seguintes ganhos políticos:

JANIO QUADROS Presidente da República (...) dará a Nação, mais fartura com TRATORES na lavoura (...) mais estradas, mais navios mercantes e de cabotagem, mais máquinas e vagões, mais CASAS POPULARES, mais hospitais e sanatórios, mais escolas, mais amparo ao trabalhador do campo e da cidade (...) Se és patriota, imprime e divulga por todo o Território Nacional.

O conteúdo deste folheto diz respeito a uma propaganda escrita localmente, com o propósito de promover voluntariamente a candidatura de JQ. ${ }^{26}$ Vidal dos Santos \& Luiz Monteiro, op. cit. p. 197-198. 
Trata-se de uma paródia da oração do Pai Nosso, por meio da qual surgem críticas à administração vigente supostamente por não conseguir assegurar condições dignas de sobrevivência a setores da população, assim como por manifestar indiferença diante disso; afirmações que trazem consigo, implicitamente, a noção de rompimento de contrato. Por outro lado, JQ é tratado como aquele que proverá tais pessoas tanto com essas almejadas condições de vida quanto com a ampliação da infraestrutura capaz de melhorá-las.

Ao que tudo indica, discursos como o de JQ, clamando pela propagação voluntária de sua imagem, encontraram ressonâncias no interior da sociedade. A carta de Francisco do Nascimento, enviada de Santo André-SP, em 7 de setembro de 1960, traz indicações sobre essa questão. Em primeiro lugar, ele pede para que JQ continue com suas atividades políticas por todo o país, tratando-o como alguém capaz de fornecer alento às esperanças de uma população atingida "pela inflação e corrupção galopante", devido à experiência dele à frente do estado de São Paulo. Depois disso, assevera de forma confiante:

Entregaremos á 3 de outubro, o Brasil a V. Excia. e cremos ve-lo de cabeça erguida (....) Vai aqui mais uma vez o meu e de minha senhora Dna Daisy Borges Nascimento irrestrito apoio a V. Exa. Estamos seguindo suas ordens, cada brasileiro um comite ambulante, já visitamos nas horas de folga, 231 familia, com 511 eleitores desta 483 (...) estão conosco, devo esclarecer, que estas famílias não são Evangelicos afora com os evangelicos o nosso modesto trabalho tem sido mais proveitoso em virtude da amizade e confiança que gozamos entre a familia evangelica.

Trata-se de uma clara demonstração de apoio político a JQ. No que concerne à afirmação de que o remetente e sua esposa assumiram o papel de "comite ambulante" da campanha janista, tal qual solicitado pelo candidato, há detalhes no texto acima que dão credibilidade a essa versão: a contabilização do número de famílias, eleitores e a quantidade de apoio recebido. Não são números arredondados ou casuais que aparecem no relato, são valores precisos e proporcionais; o número de eleitores é maior do que a quantidade de famílias, e o número de apoiadores da candidatura é menor do que o número de eleitores. Portanto, essas constatações são pistas significativas para descartarmos a hipótese de que o remetente simplesmente inventou dados para convencer JQ de seu prestígio; ao invés disso, tudo indica que ele de fato assumiu a condição de arauto da candidatura janista. 
Assim, pouco a pouco é possível problematizar a ideia de que a propaganda janista foi feita única e exclusivamente por uma estrutura orgânica, cujas articulações de cúpula contribuiriam para mistificar o restante da sociedade. $\mathrm{Na}$ verdade, como já vimos, essa era uma posição muito comum entre opositores e inimigos de JQ, utilizada para desqualificá-lo no âmbito dos embates políticos. Interpretação que também foi utilizada para atacar a atuação do MPJQ, conforme indica trecho de uma coluna de opinião do jornal Última Hora, em 5 de março de 1959: "Dentro de uma técnica meticulosamente preparada, os empresários já estão distribuindo vassourinhas para lapela, postais, portas, etc. (...) Dizem que a vassoura varre, mas as donas-de-casa sabem, de há muito, que ela apenas espalha a sujeira". ${ }^{27}$ Nestas linhas, há uma clara tentativa do jornal em denunciar o que seria o artificialismo dos métodos e da simbologia da propaganda janista, antes com suposições do que com a exibição de evidências; aliás, como é frequente no jogo político em geral.

Já as opiniões de Carlos Ricciardi da Silva eram bem distintas daquelas veiculadas anteriormente, como aponta a sua carta, enviada do estado do Paraná e datada de 12 de outubro de 1960, na qual emerge uma representação do entusiasmo que a campanha de JQ despertou. Afirmando falar em nome dos "trabalhadores do campo" de seu estado, situado numa parte do Brasil em que "nunca os poderes centraés voltaram suas atenções" - em indicação da percepção de abandono de seu grupo social pelas ações do Estado -, ele relata:

Numca siquer durante muitas eleições se viu o povo tão entusiasmado como na campanha de V. Excia., via-se verdadeiros analfabetos empunharem vassouras de todo tipo (...) Sera a propaganda tão bem planejada que tenha provocado grande entusiasmo da parte de todos os brasileiros? Acho que tenha sido os alicerce tão bem feito pelo seu passado de critério trabalho, honestidade á favor dos brasileiros, e do Brasil (...)

Na verdade, esta exibição de clareza quanto aos critérios para apoiar JQ é apenas uma parte da carta. No restante do texto, o remetente critica a concessão de aposentadorias a pessoas ainda em condições de trabalhar e, com especial ênfase, a partidarização de órgãos públicos ou a transformação destas instituições em instrumentos para o atendimento de fins privados; o que $o$ atingiria particularmente no momento de requerer empréstimos junto a bancos públicos.

\footnotetext{
${ }^{27}$ Coluna de Última Hora, “A Razão dos Símbolos”, UH-RJ, 05/03/59, p. 3.
} 
São essas algumas das razões por ele elencadas para ser "um propagandista" do "homém da vassoura", tido como alguém que modificará essa situação. Esse relato impressiona, pois, pelo modo como o missivista identifica racionalmente alguns de seus problemas como provindo do modo pelo qual o país era governado, investindo nas propostas de um candidato suas esperanças de transformar o quadro vigente; e logo ele, um trabalhador rural, personagem central de muitas teorias sobre o "populismo", na suposta condição de indivíduo despreparado para exercer seus direitos civis e políticos e inclinado a aderir a lideranças demagógicas ${ }^{28}$.

Na propaganda voluntária do candidato, há indícios de que algumas pessoas tomaram para si a tarefa de discursar publicamente em nome dele. É o que sugere a carta de Luiz de Góes, enviada da cidade do Rio de Janeiro e datada de 2 de outubro de 1960, na qual o mesmo assevera transcrever o esboço do modo pelo qual fez a propaganda presidencial falando em ônibus, botequins e ruas contra o legado varguista. Nela, o missivista declara que procurou meios para tentar desfazer o slogan "Voto em qualquer um porque todos são iguais", que seria muito difundido entre a população, através de uma linguagem considerada vulgar:

Então passei a dizer (...) todos os pinicos são iguais quando tem tampa e aza para ser segurado. Muito bem... (...) Entretanto, há pinicos que o caro eleitor aqui presente jamais colocaria êle em sua própria cabeça por estar ele cheio e transbordando de fezes isto é, materia federênta (...) São 3 os candidatos iguais física e biologicamente falando; entretanto bem diferentes civica e moralmente falando (...).

E ele segue elencando e diferenciando os candidatos:

O nome de um deles chega até ser um palavrão. Já governou com uma corrióla de tubarões e respondeu processo por peculato (...) O segundo é filho adotivo da gang que avassalou o Paiz desde 1930 e, enguliu a Constituição 2 vezes (...) O terceiro candidato (...) Jânio Quadros não é, e nunca foi cria e nem protegido de Getulio Vargas. (...) Como vereador, Deputado Prefeito e governador de São Paulo não entregou a ilha de Fernando de Noronha aos gringos e nem comprou ferro velho restos da guerra da Coreia para a parada de 7 de setembro (...).

É claro que esse documento não encerra a percepção da dimensão exata dos acontecimentos - como todo documento, aliás -, de modo que ficamos intrigados se o missivista realmente percorreu lugares públicos divulgando

\footnotetext{
${ }^{28}$ Sobre essa questão, ver: Jorge Ferreira, op. cit. p. 65.
} 
a candidatura de JQ. De qualquer maneira, esse texto pode ser considerado ao menos como uma forma de como o mesmo imaginou a publicidade para promover o candidato à Presidência de sua preferência; e é difícil aceitar, aliás, que ele não tenha compartilhado com outras pessoas tais opiniões, ou que outras pessoas não tenham compartilhado tais opiniões com ele.

É possível vislumbrar ali a presença de claras diferenciações de três candidatos à Presidência a partir da comparação de algumas de suas realizações passadas e de suas condutas públicas. $\mathrm{E}$ os recursos didáticos utilizados pelo autor para divulgar tais opiniões, através de analogias e de linguagem vulgar - longe de delinearem os contornos de uma suposta massa despolitizada -, fornecem indícios dos termos em que o público exposto às mesmas compreendia e discutia política.

Em meio a essas evidências de que a campanha janista contou com muitos propagandistas voluntários em seu nome, surgem também traços de que o mesmo ocorreu no que diz respeito à propaganda contrária ao candidato. Isso fica sugerido na carta do prefeito de Corumbataí-SP, datada de 5 de outubro de 1960, na qual emergem queixas sobre supostas atividades daquele tipo:

ontem dia 4, tomei conhecimento que um funcionário da Coletoria Federal local, senhor José Venturoli, exibiu sexta-feira última, nos bares desta cidade e diversos locais, um cartão imoral, com uma fotografia de V. Excia., de um lado e que dizia: Ontem eu era assim e do outro lado, estava V. Excia., sem roupa e de quatro pés e um homem servindo-se de V. Excia (...).

No restante da carta, há uma passagem que merece especial cuidado, nomeadamente, quando o remetente pede a JQ providências quanto a isso, afirmando que, caso contrário, "eu mesmo as tomarei e essas serão trágicas". Em outras palavras, ele procura persuadir o presidente eleito a punir o referido homem, o que bem poderia ser o artifício de alguém querendo comprometer uma pessoa com quem tem desacertos pessoais. De toda forma, mesmo que tal situação seja possível, é pouco provável que o missivista procurasse convencer JQ disso com uma prática que não fosse comum: a propaganda voluntária contrária a este último.

No que tange à propaganda oficial janista, é curioso também como muitas pessoas parecem ter optado por distribuir voluntariamente o material publicitário produzido pelo núcleo central da campanha. É o que está indicado numa carta endereçada a Quintanilha Ribeiro, amigo pessoal de JQ e um dos principais articuladores de sua candidatura, com assinatura difícil de 
se identificar e enviada de Campos Novos-SC, em 16 de junho de 1959, em que o remetente apresenta uma notificação de recebimento de propaganda eleitoral e relata o uso que teria sido dado à mesma:

Dia a dia nota-se melhora no ambiente político, Esclarece-se o lavrador e ele compreende, como fosse um milagre e pasa a trabalhar na campanha, a penetração no setor rural é notável e entre o pequeno comércio é simplesmente fantastica. (...) A solicitação de propaganda é enorme, principalmente para ser levada a distribuir em zonas triticolas, agricolas e Rurais, principalmente para as regiões onde predomina o trabalho em regiões colonizadas por alemães e italianos. O movimento popular Jânio Quadros é original, é contaminador (...).

Em seguida, o missivista esclarece como estas atividades são para ele e seu grupo social, de trabalhadores rurais, uma forma de participação política em meio a constrangimentos supostamente colocados pela forte presença em seu município do PSD, de "cabresto". E ele apresenta razões plausíveis para ter empreendido efetivamente tais ações, tendo em vista seus descontentamentos com a administração então vigente:

Eu como Presidente da (...) Regional da Ordem dos Lavradores, em nome desta honrada e desamparada classe à qual eu me orgulho pertencer. Não desejo mais que um pouco de amparo à classe e valorização do suor do homem. (...) Não estou mal porque tenho outros meios, mas existem aqueles que plantam por profissão, e só tinham o trigo para pagar o armazem e comprar pelucia e alparcatas para os filhos no inverno (....) Enquanto isto gasta-se mais de dois Biliões para a Séde do Banco do Brasil em Brasília e quase três Bilhões para seus funcionários!!!!

O engajamento voluntário de muitas pessoas na propagação da figura de JQ não significa que outras pessoas não tenham preferido associar-se ao MPJQ. É o que aponta, por exemplo, a missiva de Nivio Previato, enviada de Andradas-MG com data de 9 de julho de 1960, em meio a queixas do remetente pelo não atendimento de sua solicitação em ter seu grupo de correligionários incorporado ao movimento: "Releva notar que a iniciativa da organisação do Comitê foi resultado da geral simpatia que o nome de V. Excia. desfruta neste município e, como verdadeiros idealistas, quizemos assim centralizar numa organização política uma propaganda eficiente e produtiva. (...)”. Estas linhas, portanto, apontam a presença de uma pressão externa ao MPJQ no sentido de aumentar o seu alcance, baseada na opinião e no julgamento de simpatizantes 
de JQ; e não simplesmente a ampliação do movimento de cima para baixo, a partir de uma técnica meticulosamente planejada.

Aliás, as numerosas adesões de pessoas ao MPJQ por todo o país - por mais que os membros dirigentes deste último negassem o seu envolvimento com legendas partidárias - parecem ter contribuído para a percepção de que o movimento tinha condições de se institucionalizar como partido. É o que atesta uma circular reservada do MPJQ, assinada por Castilho Cabral e distribuída pelos comitês do movimento ao longo do território nacional, com data de 12 de setembro de 1960 . Nela, são expressas algumas inquietações sobre o futuro do MPJQ e colocadas algumas possíveis alternativas acerca do seu estatuto, a saber:

a) dissolução, pura e simples, do MPJQ;

b) manutenção do MPJQ, como associação civil não partidária, tendo por precípua finalidade sustentar o programa de Govêrno de Jânio Quadros;

c) transformação do MPJQ em partido político - o esperado grande partido de base popular, não pelego comunista, instrumento adequado ao aperfeiçoamento da democracia e ao desenvolvimento do Brasil, como um todo e em todos os sentidos, fiel às suas origens e em sintonia com o mundo (o programa de Jânio, em suma). ${ }^{29}$

A elaboração e a adjetivação crescentes das alternativas indicam que as mesmas foram tecidas com o objetivo de convencer os integrantes do MPJQ da existência de uma hierarquia entre as opções apresentadas; e a preferência recai evidentemente na última escolha. É importante lembrar que a discussão sobre a possibilidade de o movimento ser transformado em partido atingiu um público mais amplo do que aquele composto pelos seus integrantes, na medida em que o conteúdo da circular acima foi publicado na revista Manchete, de circulação nacional, pouco depois. ${ }^{30}$

E, segundo a versão de Castilho Cabral, essa ideia contava com a simpatia do próprio JQ que, em determinada ocasião durante seu mandato presidencial, teria proposto a ampliação e a consolidação do MPJQ: "Saí do palácio do Planalto satisfeito especialmente com a idéia de Jânio de maior

\footnotetext{
${ }^{29}$ Arquivo pessoal Castilho Cabral, CPDOC-FGV, CCc 59. 04. 13, I-72.
}

30 “Já existe o partido de Jânio Quadros?", Manchete, 26/11/60, p. 17-18. 
extensão e melhor aproveitamento do MPJQ, base de um poderoso partido novo (...)". ${ }^{31}$ Em outras palavras, há evidências de que correntes da opinião pública eram canalizadas no âmbito do MPJQ, conferindo-lhe a condição de partido de fato.

\section{Considerações finais}

Com a análise anterior sobre a projeção política de JQ, espero, sobretudo, ter contribuído com as críticas ao conceito de populismo. Seja pelo conhecimento de sua experiência administrativa em outros cargos públicos, seja pelas suas proposições de combate à corrupção e do oferecimento de condições mais dignas de vida à população, muitas pessoas parecem ter se transformado em propagandistas voluntários de JQ: em exibição clara dos motivos e interesses que as levaram a apoiar o candidato, de quem esperavam obter ganhos materiais ou simbólicos.

Em primeiro lugar, o grande número de pessoas promovendo a candidatura janista, através de versos e músicas, pareceu-me ser um contraponto interessante em relação às posições de adversários de JQ, que o tratavam apenas como um constructo artificial de uma propaganda planejada. Em segundo lugar, os desdobramentos desse tipo de investigação, na correspondência analisada, logo trouxeram à baila casos de pessoas que parecem ter produzido e divulgado voluntariamente propaganda política em nome dele. Seja escrevendo panfletos, fazendo discursos em praça pública, ou distribuindo material publicitário oficial do candidato, simpatizantes de JQ identificaram nessas atividades um meio de defender seus interesses na arena política, e tentar convencer outras pessoas acerca das vantagens de seus pontos de vista. Em outras palavras, ao fazerem propaganda no sentido mais elementar do termo, no ato de propagar a imagem de um candidato cujos passado e propostas afiguravam-se-lhes como as melhores alternativas num leque de escolhas, estavam fazendo política.

Cabe lembrar que tal mobilização do eleitorado foi feita, em larga medida, com propostas de governo e legendas partidárias. Uma análise da atuação de JQ, durante o período em que disputou as eleições presidenciais, revela que o mesmo pautava-se por projetos políticos, notados principalmente na defesa da Política Externa Independente e de posições semelhantes ou até mesmo coincidentes com o ideário da democracia cristã: defender condições

${ }^{31}$ Castilho Cabral, op. cit. p. 233. 
de vida mais dignas e a valorização do ser humano, em meio ao surto desenvolvimentista que promovia acelerado crescimento econômico às expensas de um notável aumento do custo de vida, mostrar-se-ia uma proposição sedutora para os grupos sociais que se sentiam prejudicados com essas transformações. Tais considerações não devem obscurecer o fato de que a consolidação da força política de JQ, além do seu personalismo, contou com o apoio de grupos empresariais nacionais e internacionais e de grandes partidos do período, como a UDN. Da mesma forma, ainda que não tratada especificamente nas linhas anteriores, não se deve descartar a hipótese de que sua renúncia à Presidência pode ter sido uma tentativa de forçar sua volta ao cargo sem os limites da Carta constitucional.

De qualquer modo, tratá-lo simplesmente como um desequilibrado que conquistou o principal cargo público da República brasileira simplesmente com lances histriônicos, é endossar as posições de seus inimigos que parecem ter se cristalizado na memória coletiva após a renúncia; e é deixar de lado como seus atos e propostas políticas foram capazes de mobilizar amplos setores da sociedade brasileira que discutiam e reverberavam tais atributos, contribuindo assim para a moldagem de um novo partido político que esteve prestes a se institucionalizar. 